\title{
A Training Program Supported with Some Alternative Tactics and its Effects on Improving the Performance Level of the Vast Fast-Break Strategy for Junior Handball Players.
}

\author{
Ahmed Mohamed Zaki Hasaballa
}

Lecturer, Faculty of Physical Education - Tanta University. Egypt.

\begin{abstract}
The current research aims at designing a recommended training program supported with some alternatives of the vast fast-break strategy to identify the effect of using this strategy on improving some physical, technical and tactical characteristics and the effect of training on the three tactical alternatives on the mean of its performance time and the mean of vast fastbreak strategy performance time. The researcher used the quasi-experimental approach (onegroup design) with pre- and post-measurements. Research community included members of the Middle Delta handball team for 2012-2013 seasons. Subjects $(n=24)$ were junior handball players from Tanta Sports Club Team who are purposefully chosen for this research. They are divided into (4) equal groups (6 players each) as follows: group (1) for the strategy group (2) for first tactical alternative - group (3) for second tactical alternative - group (4) for third tactical alternative. Each group performed (7) trials. This is due to the nature of team tactical performance. The researcher concluded that tactical alternatives exercises have positive effects on performing the vast fast-break strategy in junior hand ball players as it led to improving several variables like: Physical variables (2.81\%: 13.9\%) - Technical variables (18.48:57.29\%) - Duration of performance for tactical alternatives of the strategy phases (40.98\%:41.51\%) - Duration of performance of the vast fast-break strategy (40.98\%).
\end{abstract}

Key words: Junior Handball Players - Vast Fast-Break - Alternative Tactics.

\section{Introduction:}

The motor-situational link among
members of the same team is the solid base that most coaches seek to support in their teams so that team performance becomes more sequential, dynamic and directed towards a specific goal in each tactical situation of the match. One study, analyzing the European Championship, pointed out that the first 6 teams had dominant attitudes towards fast-break as each player followed specific running paths for his position. The basic situation of the team is attacking with two players on the circle and the first phase of counter-attack should be effective. During counter-attack, the team should not replace more than one player and during the final phase of counter-attack one back player should shoot from distance through gaps in the opponent's defense (Hianik, J. 2008, P: 1). Another study indicated that team tactical formation is a tactical performance that helps employing all available capabilities of players and using the specific characteristics of each player through distributing tasks according to each player's status and capabilities in addition to time and place considerations. It should not include more than 4 players; the goal keeper 
may be one of them, with maximum duration of 5 seconds of ball possession and includes 6:10 motor performances (Nenade et al 2004, P74). It is clear that there is a relation between "strategy" and factors affecting it; as each tactical move has a specific technical level (Garganta J. 2009 81-89). The increase of technical level corresponds with an increase in the tactical level. A player who does not master the skill may concentrate on maintaining the ball and this decreases his/her concentration to find the correct tactical solution necessary for the specific game situation. Therefore, there is a close link between tactical and technical performances and cooperation among team players plays a major role in fulfilling the final goal of the team (Breed, Ray and Spittle, Michael 2012, pp. 19-20)

The researcher thinks that the success of any team fast-break "strategy" depends on fulfilling several conditions and during training the coach should concentrate on fulfilling these conditions. Technical training should be performed through training players on skills with and without the ball and tactical training should be performed through tactical formations with two or more players including movement without the ball, timing and motor synchronization among players. Through analyzing the $22^{\text {nd }}$ championship for men in Sweden, it was clear that the rebound and transition from defense to attack improved significantly as many teams, including France (the world champion team) used active defense that usually begins from the half court of the opponent to exhaust the rebound attack. In addition, the phase of organizing defense was very important as the opponent's break throws were attacked with active defenses to force the opponent rebuild the attack (The International Federation of Handball's Journal, 2011, P: 8). As a head coach of Tanta Sports Club team, the researcher can assure that vast fast-break is one of the most important components for training junior players on attack, especially those who are less than 14 years as the previous stage is the mini-handball where the nature of play is mostly unorganized and the beginning of tactical commitment is from 14 years.

This led the researcher to perform this research to identify the effects of training on the general "strategy" of fast-break and mastering it so that the player has a total picture of the tactical performance of fastbreak in addition to training the player, and the team as well, on problem solving through training on situational tactical alternatives during performance. This is consistent with previous studies indicating that vast team fast-break has a top priority in match results on the international level, especially if it is done through systematic work based on finding solutions and alternatives. These studies indicated the importance of designing training programs specific for situations during real performance (Mark Pfeiffer \& Andreas Hohmann 2012 : 344-359 , Craig, Cathy \& Watson, Gareth 2011: PP: 689-708, Santiago, Catarina B.; Reis, Luis Paulo; Rossetti, Rosaldo \& Sousa, Armando 2011: pp 761 , Gloeckner, Andreas; Heinen, Thomas; Johnson, Joseph G. \& Raab, Markus 2010 : PP: 318-333 , Cavala, Marijana \& Katic, Ratko2010 : PP: 13551361 , Hianik , J 2008 : 22:22-29.pp. 1 , Ohnjeck.et at 2008 : PP: 761-766 , Gruic,d.and milanvic,D 2006 : pp 164-175, Shog ,Roguli , n. and katiic , R 2001 : coll antropol 25, PP: 611-617)

Aim:
$\begin{aligned} & \text { 1. Identifying the effects } \\ & \text { recommended }\end{aligned}$ of a
training program


supported with some alternatives of the vast fast-break strategy on improving some physical (transitive speed, agility and hand-eye coordination) and technical (pass from running, pass length and accuracy and jump shot) characteristics.

2. Identifying the effects of a recommended training program supported with some alternatives of the vast fast-break strategy on the mean performance duration of the three tactical alternatives (possession and take off, building up and decision making and preparation for ending)

3. Identifying the effects of a recommended training program supported with some alternatives of the vast fast-break strategy on the mean performance duration of the vast fastbreak strategy.

\section{Hypotheses:}

1. There are statistically significant differences between the pre- and postmeasurements of some physical (transitive speed, agility and hand-eye coordination) and technical (pass from running, pass length and accuracy and jump shot) characteristics in favor of the postmeasurements.

2. There are statistically significant differences between the pre- and postmeasurements of the mean performance duration of the three tactical alternatives (possession and take off, building up and decision making and preparation for ending), in favor of the post measurements.

3. There are statistically significant differences between the pre- and post- measurements of the mean performance duration of the vast fastbreak strategy in favor of the postmeasurements.

4. Terminology:

- Strategy (procedural):

It is a general pattern of motor performance and a set of total principles to be trained that may happen in matches so that players' responses to them become autonomous and synchronized.

- Vast Fast-Break:

The goal keeper $(\mathrm{G})$, standing under the beam, runs to the opposite stand of the (CB) station and possesses the ball. Then he moves correctly and passes to (CB) then (CB) passes to (LB) and runs to (LB) station. (LB) passes to (LW) then descends to the $6 \mathrm{~m}$ circle from the opposite direction. At the same time, player (L) descends to the $6 \mathrm{~m}$ circle below (LB) station. (LW) moves to the goal and passes to $(\mathrm{CB})$ in (LB) station. (CB) moves forwards and passes to (RB) at the other side of the court. (RB) moves forward and passes to (RW) who shoots from the wing towards the opponent's goal.

Fig (1) Vast Fast-Break strategy

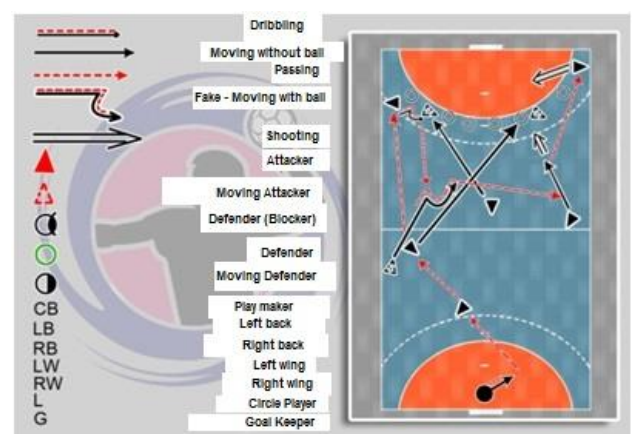

- Tactical Alternatives (procedural):

These are specific patterns of motor performance according to total principles. These are trained on as possible situations for facing the opponent's defense in one of the 
phases of general strategy of vast fast-break so that players' responses to them become autonomous and synchronized.

- First Phase (Possession and take-off):

This phase begins with the end of opponent's attack (technically and legally) until it reaches the beginning player for the attack; either he is a play maker, left or right wings of circle player.

Fig (2)

Possession and take-off phase
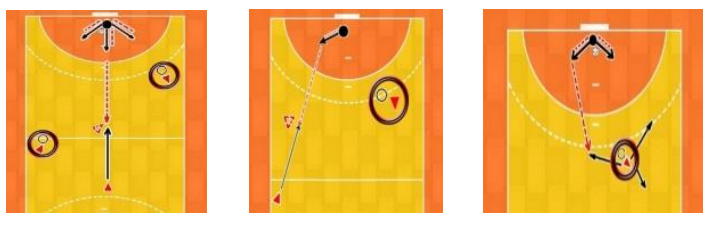

- Second Phase (Building up and Decision Making):

This phase begins after the end of the pass from the beginning player and ends with two players stationing on the circle. Those are left or right wings or circle player.

Fig (3)

Building up and Decision Making Phase
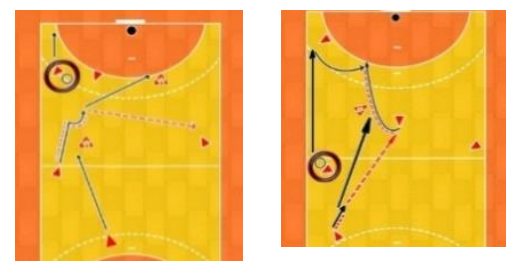

- Third Phase (Preparation for Ending):
This phase begins with the streaming of the ball after reaching (2/4) formation and ends with shooting to the opponent's goal.

Fig (4)

Preparation and Ending Phase
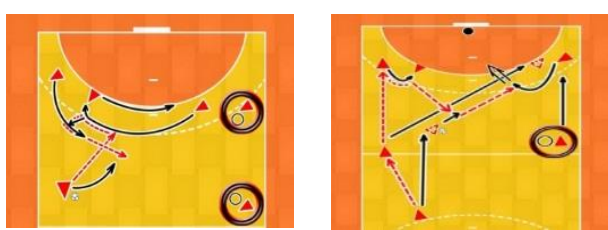

\section{Methods:}

\section{Approach:}

The researcher used the quasiexperimental approach (one-group design) with pre- and post-measurements.

\section{Subjects:}

Research community included members of the Middle Delta handball team for 2012-2013 season. Subjects $(n=24)$ were junior handball players from Tanta Sports Club Team who are purposefully chosen for this research. They are divided into (4) equal groups (6 players each) as follows: group (1) for the strategy - group (2) for first tactical alternative - group (3) for second tactical alternative - group (4) for third tactical alternative. Each group performed (7) trials. This is due to the nature of team tactical performance. Table (1) shows the statistical description of the subjects. 
Table (1)

Subjects description on all research variables $(n=24)$

\begin{tabular}{|c|c|c|c|c|c|c|c|}
\hline Type & Variable & Measurement & Mean & Median & SD & Kurtosis & Skewness \\
\hline \multirow{4}{*}{$\begin{array}{c}\text { Basic } \\
\text { variables }\end{array}$} & Age & Year/day & 12.78 & 12.80 & 0.16 & 0.94 & $0.34-$ \\
\hline & Height & $\mathrm{Cm}$ & 164.88 & 165.00 & 3.34 & $0.55-$ & $0.25-$ \\
\hline & Weight & Kg & 61.63 & 62.00 & 5.62 & 0.24 & $0.48-$ \\
\hline & Training age & Year/day & 5.96 & 6.00 & 69. & 0.71- & $0.05-$ \\
\hline \multirow{3}{*}{ Physical } & Transitive speed & Sec & 4.89 & 4.90 & 0.18 & 0.88- & $0.16-$ \\
\hline & Agility & Sec & 10.79 & 11.00 & 0.72 & $0.91-$ & $0.34-$ \\
\hline & Hand-eye coordination & $\operatorname{Rep}$ & 16.17 & 16.00 & 1.03 & 0.66 & $0.49-$ \\
\hline \multirow{3}{*}{ Technical } & Pass from running & Rep/sec & 20.29 & 20.00 & 1.08 & 0.59 & 0.19 \\
\hline & Pass length and accuracy & Point & 6.67 & 8.00 & 2.87 & 1.84 & $1.51-$ \\
\hline & Jump shot & number & 4.00 & 4.50 & 1.25 & 0.16 & $1.20-$ \\
\hline
\end{tabular}

Table (1) indicates that data is free of radical distributions. This indicates subjects' homogeneity.

Table (2)

Description of number of trials according to performance duration $(n=7)$

\begin{tabular}{|c|c|c|c|c|c|c|}
\hline Variable & Measurement & Mean & Median & SD & Kurtosis & Skewness \\
\hline Duration of Vast fast-break & Sec & 8.69 & 9.00 & $\mathbf{0 . 5 8}$ & $\mathbf{0 . 8 4}-$ & $1.60-$ \\
\hline Duration of Possession and take-off & Sec & 7.71 & $\mathbf{8 . 0 0}$ & $\mathbf{0 . 4 9}$ & $\mathbf{0 . 8 4 -}$ & $1.77-$ \\
\hline $\begin{array}{c}\text { Duration of Building up and decision } \\
\text { making }\end{array}$ & Sec & 7.57 & 7.50 & $\mathbf{0 . 5 3}$ & $\mathbf{2 . 8 0}$ & $\mathbf{0 . 3 9}$ \\
\hline Duration of Preparation and ending & Sec & 7.43 & 7.50 & $\mathbf{0 . 6 1}$ & $\mathbf{2 . 8 0}$ & $\mathbf{0 . 3 4 -}$ \\
\hline
\end{tabular}

Table (2) indicates that data is free of radical distributions. This indicates trials' homogeneity.

\section{Data Collection Instruments:}

After review of literature and according to experts' opinions, the researcher used the following:

\section{Equipment:}

A restameter for measuring heights - a medical balance for measuring weights - a stop watch - a measuring tape - chalk cones -15 tennis balls -25 hand ball balls a screen - a VCR.

\section{Tests:}

The researcher used experts' opinions form for validating the technical and tactical requirements of the strategy, the best strategy for vast fast-break and the four alternatives of the strategy. In addition, experts' opinions were used for verifying the tests of these alternatives. (Appendix 1). Experts' opinions indicated that physical variables and its corresponding tests are as follows: speed (30m running from flight), agility (Nebraska Test) and hand-eye coordination (ball throw to the wall). Technical variables and its corresponding tests are as follows: short passing (pass from running lift and right), long passing (passing length and accuracy for $30 \mathrm{~m}$ ) and shooting (10 balls jump shots). In addition, experts indicated that the performance duration of the fast-break strategy is the sum of performance durations 
for its three phases (possession and take off building up and decision making preparation for ending). Validity and reliability tests for these instruments indicated that they are valid and reliable.

\section{The training Program:}

According to the review of literature (Mark Pfeiffer \& Andreas Hohmann 2012 : 344359, Craig, Cathy \& Watson, Gareth 2011: PP: 689-708, Gloeckner, Andreas; Heinen, Thomas; Johnson, Joseph G. \& Raab, Markus 2010 : PP: 318-333, Cavala, Marijana \& Katic, Ratko2010 : PP: 13551361, ( Hianik , J 2008 : 22:22-29., Ohnjeck.et at 2008 : PP: 761-766, Gruic,d.and Milanvic, D 2006 : pp 164-175 , Shog ,Roguli , n. and katiic , R 2001 : coll antropol 25 PP: 611-617) and experts' opinions the researcher followed the following steps in designing the recommended training program:

- The vast fast-break strategy was divided into three gradual phases and tests for measuring its performance duration were designed.

- General aims of the recommended training program are improving some physical variables (transitive speed agility - hand-eye coordination) and technical performances (passing from running - length and accuracy of passing - jump shots), in addition to the mean performance duration of the three tactical alternatives and the mean performance duration of the strategy as a whole. Each sub-phase had specific aims as follows:

- Phase one (possession and take off): to improve tactical performances that begin technically and legally at the end of the opponent's attack until the ball comes to the player who begins the attack (playmaker [CB] - right/lift wing [RB-LB] - circle player [L]) as this improves the technical and physical performances.

- Phase two (building up and decision making): to improve tactical performances beginning with a pass from the player who begins the attack and ends with two players stationing on the circle, one of them is the lift/right wing $[\mathrm{LB}-\mathrm{RB}]$ and the other is the circle player [L].

- Phase three (preparation for ending): to improve tactical performances beginning from ball rally after reaching 2/4 attack formation and ends with shooting to the opponent's goal.

- The recommended training program was designed and training loads were identified according to the research sample characteristics.

- The researcher identified and provided all needed material and human resources.

\section{Training load intensity:}

1. Work/rest ratio $=2: 1$

2. Physical aspect $=40 \%: 70 \%$ technical aspect $=50 \%: 80 \%$ - tactical aspect $=70 \%: 95 \%$

3. Total intensity of the unit equals the three aspects.

Fig (4)

Formation of Training Intensity

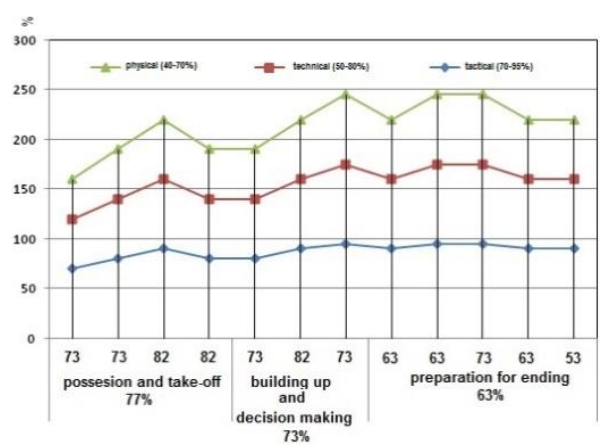


Experiment:

\section{Pre-Measurements:}

Pre-measurements were taken from 2-1-2013 to 7-1-2013

\section{Main application:}

The program was applied from 12-1-2013 to 4-4-2013 and the tactical part was immediately after warm-up.

\section{Results and Discussion:}

\section{Post-measurements:}

Post-measurements were taken from 6-42013 to $11-4-2013$

\section{Statistical treatment:}

The researcher used SPSS software to calculate the following: mean - median standard deviation - Skewness - correlation coefficient - (t) test. Significance was measured on $\mathrm{P} \leq 0.05$

Table (3)

Difference significance between pre- and post-measurement of subjects on physical and technical variables

$(n=24)$

\begin{tabular}{|c|c|c|c|c|c|c|c|c|c|}
\hline & \multirow{2}{*}{ Tests } & \multicolumn{2}{|c|}{ Pre- } & \multicolumn{2}{|c|}{ Post- } & \multirow{2}{*}{ 胥 } & \multirow{2}{*}{ 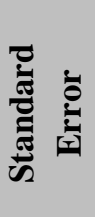 } & \multirow{2}{*}{ (t) } & \multirow{2}{*}{ 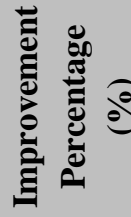 } \\
\hline & & Mean & SD & Mean & SD & & & & \\
\hline $\mathbf{1}$ & 30m running from flight & 4.89 & 0.18 & 4.75 & 0.17 & 0.14 & 0.03 & $* 4.12$ & 2.81 \\
\hline 2 & Nebraska & 10.79 & 0.72 & 9.29 & 0.81 & 1.50 & 0.23 & $* 6.43$ & 13.90 \\
\hline 3 & Throwing balls to wall & 16.17 & 1.03 & 16.63 & 1.20 & 0.46 & 0.21 & $* 2.18$ & 2.83 \\
\hline 4 & $\begin{array}{l}\text { Passing from running } \\
\text { (going only) to left and right }\end{array}$ & 20.29 & 1.08 & 16.54 & 1.18 & 3.75 & 0.33 & $* 11.3$ & 18.48 \\
\hline 5 & $\begin{array}{l}\text { Pass length and direction } \\
\text { accuracy from } 30 \mathrm{~m}\end{array}$ & 6.67 & 2.87 & 9.75 & 4.13 & 3.08 & 1.02 & $* 6.26$ & 46.18 \\
\hline 6 & $\begin{array}{l}\text { High jump shooting } \\
\text { (10 balls) }\end{array}$ & 4.00 & 1.25 & 6.29 & 1.37 & 2.29 & 0.46 & $* 5.02$ & 57.29 \\
\hline
\end{tabular}

(t) Table values on $\mathbf{P} \leq \mathbf{0 . 0 5}=\mathbf{1 . 7 1}$

From table (3) and according to previous studies (Stanislaw, Z. and H. Duda, 2005 p.284, Cavala, Marijana \& Katic, Ratko 2010 : PP: 1355-1361, Agnienszna Jadach 2005:pdf, Chelly, MS, Hermassi, S, Aouadi, R, Khalifa, R, Van den Tillaar, R, Chamari, K, and Shephard, RJ. PP: 2410-2417, 2011) we can conclude that players with high technical levels are characterized by higher levels of basic speed, coordination, agility and coordinative abilities, compared with their peers of poor technical levels. The researcher thinks that these improvements are due to the recommended training program that includes technical drills that have positive effects on the physical variables under investigation. In addition, the aforementioned studies indicated that specific physical characteristics of handball can be developed through training on technical aspects of performance, especially for junior players as improving the physical aspects can be accompanied with technical aspects. 
Furthermore, table (3) and previous studies (Hianik , J 2008 : 22:22-29, Cavala, Marijana \& Katic, Ratko 2010 : PP: 1355-1361, Daniel Memmert 2010 PP: 199 - 205) indicated that technical training has positive effects on all types of passing and jump shooting from the back area. These studies indicated also that fast-break needs technical aspects for being success, including skills with and without ball.

Table (4)

Difference significance between pre- and post-measurement of subjects on tactical alternatives variables $(n=7)$

\begin{tabular}{|c|c|c|c|c|c|c|c|c|c|}
\hline & \multirow{2}{*}{ Tests } & \multicolumn{2}{|c|}{ Pre- } & \multicolumn{2}{|c|}{ Post- } & \multirow{2}{*}{ 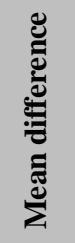 } & \multirow{2}{*}{ 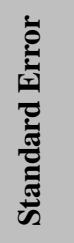 } & \multirow{2}{*}{ (t) } & \multirow{2}{*}{ 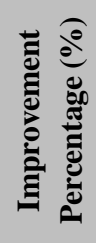 } \\
\hline & & Mean & SD & Mean & SD & & & & \\
\hline 1 & $\begin{array}{c}\text { Performance duration for } \\
\text { possession and take-off phase }\end{array}$ & 7.71 & 0.49 & 4.56 & 0.98 & 3.15 & 0.26 & *12.13 & 40.89 \\
\hline 2 & $\begin{array}{l}\text { Performance duration for buildup } \\
\text { and decision making phase }\end{array}$ & 7.57 & 0.53 & 4.43 & 0.79 & 3.14 & 0.28 & *11.22 & 41.51 \\
\hline 3 & $\begin{array}{c}\text { Performance duration for } \\
\text { preparation and ending phase }\end{array}$ & 7.43 & 0.61 & 4.32 & 0.98 & 3.11 & 0.22 & *14.25 & 41.85 \\
\hline
\end{tabular}

(t) Table values on $\mathbf{P} \leq \mathbf{0 . 0 5}=1.94$

Table (4) and previous studies ((Craig, Cathy \& Watson, Gareth 2011: PP: 689-708, Shog ,Roguli , n. and katiic , R 2001 : coll antropol 25 PP: 611-617)) indicated that training on tactical formation and skill with/without the ball is important in modern handball. In addition, it indicated the importance of taking good situational decisions, training on fast-break against the opponent's defenses and using total tactical components as all these factors differentiate between winners and losers in team handball.

The researcher thinks that the improvements are due to the training program as it includes exercises that improved test results of the tactical alternatives. These exercises were gradual and work on various parts of the court. In the first phase (possession and takeoff) the program included exercises to overcome obstacle of ball possession like balls far from the goal keeper or not seeing the ball, in addition to ball control exercises, then speed up and passing exercises for the beginning player and exercises for changing and modifying decisions according to court and opponent variability. Then players exercise on alternatives during this phase (play maker $\mathrm{CB}$, left or right back $\mathrm{LB}-\mathrm{RB}$ or circle player C) under the opponent's pressure and this improved the duration of performing these alternatives. During the second phase (build up and decision making), players exercise on finding solutions for the beginning player and training him on these solutions, either as LB - RB who is near the playmaker or as the LW - RW (left or right wings). These exercises led to solutions being automatically initiated and this led to speeding up decision making and moving with or without the ball. All this improved the duration of performing these alternatives. During the third phase (preparation and ending) the players exercise on ending the attack after decision making through finding 
solutions for the ending player either through LB - RB or LW - RW. These exercises led to solutions being automatically initiated and this led to improving the ending of the task. All this improved the duration of performing these alternatives.

Table (5)

Difference significance between pre- and post-measurement and percentage of improvement of subjects on the strategy variable $(n=7)$

\begin{tabular}{|c|c|c|c|c|c|c|c|c|c|}
\hline & \multirow{2}{*}{ Tests } & \multicolumn{2}{|c|}{ Pre- } & \multicolumn{2}{|c|}{ Post- } & \multirow{2}{*}{ 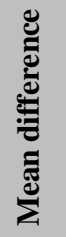 } & \multirow{2}{*}{ 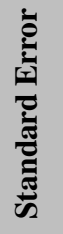 } & \multirow{2}{*}{ (t) } & \multirow{2}{*}{ 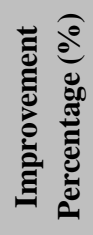 } \\
\hline & & Mean & SD & Mean & SD & & & & \\
\hline 1 & $\begin{array}{l}\text { Performance duration of } \\
\text { fast-break strategy }\end{array}$ & 8.69 & 0.58 & 5.12 & 0.69 & 3.57 & 0.20 & $* 17.68$ & 40.98 \\
\hline
\end{tabular}

(t) Table values on $\mathbf{P} \leq \mathbf{0 . 0 5}=\mathbf{1 . 9 4}$

Table (5) and previous studies (Gutierrez, Oscar \& Ruiz, José L 2013 PP: 137-147, Garganta J. 2009 PP:81-89, Breed, Ray and Spittle, Michael 2012, pp. 19-20) indicated that improving the duration of performance is due to training on technical performances in its situational form during matches. This guarantees that each player will adapt to pressures and changing situations during the match.

The researcher thinks that improvements in the performance duration of fast-break strategy are due to the training program. The total duration of the vast fast-break strategy is the sum of all durations of performance for all players involved. During the first phase (possession and take-off) the program included exercises for the goal keeper to gain ball possession quickly from any place near the goal, either after a fault shoot, fault attack due to legal technicalities or even the ball gets out of court from either side. In addition, this phase included exercises for take-off of fast-break, beginning with the goal keeper or any other beginning player (playmaker, RB, LB, circle player) under the opponent's pressure. During the second phase (build up and decision making), the program included exercises for finding solutions for the beginning player and training him on these solutions, either as LB - RB who is near the playmaker or as the LW - RW (left or right wings). These exercises led to solutions being automatically initiated and this led to speeding up decision making and moving with or without the ball. All this improved the duration of performing the strategy. During the third phase (preparation and ending) the program included exercises for ending the attack after decision making through finding solutions for the ending player either through LB - RB or LW - RW. These exercises led to solutions being automatically initiated and this led to improving the ending of the task. All this improved the duration of performing the strategy.

\section{Conclusions:}

The researcher concluded that tactical alternatives exercises have positive effects on performing the vast fast-break strategy in junior hand ball players (less than 14 years) as it led to improving the following variables: 
1. Physical variables (speed $2.81 \%$ hand-eye coordination $2.83 \%$ - agility $13.9 \%)$

2. Technical variables (pass from running $18.48 \%$ - length and accuracy of pass $46.18 \%$ - jump shot $57.29 \%$ )

3. Duration of performance for tactical alternatives of the strategy phases (phase one $40.98 \%$ - phase two $41.51 \%$ - phase three $-41.51 \%$ )

4. Duration of performance of the vast fast-break strategy $(40.98 \%)$

\section{Recommendations:}

The researcher recommends the following:

1. Using the recommended training program for improving some tactical alternatives to train junior handball players (research sample) on vast fast-break

2. Using the recommended training program for improving some tactical alternatives to train junior handball players (research sample) on phases and alternatives of vast fast-break

3. Using the recommended training program for improving some tactical alternatives to improve some technical variables (passing shooting - moving without ball) for junior handball players (research sample)

4. Using the recommended training program for improving some tactical alternatives to improve some physical variables (speed - agility coordination) for junior handball players (research sample)

5. Replicating this research on other samples that vary in the technical levels and age groups to expand and validate results of this research 


\section{References:}

1. Agnienszna Jadach (2005):Connection between particular coordination motor abilities and Game Efficiency of young female hand ball player - team games in physical Education and sport , Poland , 2005 , http : // tkocek . net / konferencja 050 spiswproead zenic pdf

2. Breed, Ray and Spittle, Michael 2012, Developing game sense through tactical learning, Active and healthy magazine, vol. 19, no. 1, pp. 19-20

3. Cavala, Marijana \& Katic, Ratko (2010): Morphological, Motor and Situation-Motor Characteristics of Elite Female Handball Players According to Playing Performance and Position. COLLEGIUM ANTROPOLOGICUM Volume: 34 Issue: 4 PP: 1355-1361

4. Chelly, MS, Hermassi, S, Aouadi, R, Khalifa, R, Van den Tillaar, R, Chamari, K, and Shephard, RJ. Match analysis of elite adolescent team handball players. J Strength Cond Res 25(9):pp 2410-2417, 2011

5. Craig, Cathy \& Watson, Gareth (2011): An Affordance Based Approach to Decision Making in Sport: Discussing a Novel Methodological Framework. REVISTA DE PSICOLOGIA DEL DEPORTE Volume: 20 Issue: 2 PP: 689-708

6. Daniel Memmert (2010): TESTING OF TACTICAL PERFORMANCE IN YOUTH ELITE SOCCER. Journal of Sports Science and Medicine (2010) 9, 199 - 205

7. Garganta J. Trends of tactical performance analysis in team sports: bridging the gap between research, training and competition. Revista Portuguesa de Ciências do Desporto. 2009;9(1):81-89

8. Gloeckner, Andreas; Heinen, Thomas; Johnson, Joseph G. \& Raab, Markus (2010): Network approaches for expert decisions in sports. HUMAN MOVEMENT SCIENCE Volume: 31 Issue: 2 Special Issue: SI PP: 318-333

9. Gruic,d.and milanvic, $\mathrm{D}(2006)$ : performance in dicators of teams at the 2003 mens world handball championship in potugal . kinesiology 38(2006) 2: pp:164-175

10. Gutierrez, Oscar \& Ruiz, José L (2013): Game Performance versus Competitive Performance in the World Championship of Handball 2011. Journal of Human Kinetics. Volume 36, Issue 1, Pages 137-147

11. Hianik , J (2008) : Women U 17 european handball champion ship -slovakia qualitative trend analysis actakineciologica , . 22:22-29.pp. 1

12. Khaleel, Samiea (2008): Introduction to Sports Physiology, Dar Al-Nas Press - Cairo - Egypt. PP: 44-51-52-112-114 (in Arabic)

13. Mark Pfeiffer \& Andreas Hohmann (2012): Applications of neural networks in training science. Human Movement Science 31 (2012) 344-359.

14. NenadeRoguli , VatromirSrhoi , and ljerkasrkoj (2004) : The contribution of collective attack tacticsincifferentiationg handball score efficiency and education, university of split . split, Croatia pp.74

15. Ohnjeck.et at (2008) : performance indicators of team at the 2003 world handball championship for women in Croatia kinesiology 40 I PP: 761-766

16. Santiago, Catarina B.; Reis, Luis Paulo; Rossetti, Rosaldo \& Sousa, Armando (2011): Foundations for Creating a Handball Sport Simulator. SISTEMAS E TECNOLOGIAS DE INFORMACAO, VOL

17. Shog ,Roguli , n. and katiic , R (2001) : in fluence of the attack end conduction on match Result in handball . coll antropol 25pp 611-617

18. Stanislaw, Z. and H. Duda, (2005): "Coordinating Ability but efficiency of game of young football players. Team games in physical education and sport. Academy of Physical Education, Cracow, Poland, p.284

19. The international Handball Federation's Journal (2011) - the Technical Journal: training - officiating - sports medicine - AlShourta Press - Cairo - Egypt. P:8 (in Arabic) 
